Int. J. Dev. Biol. 56: 245-254w

doi: $10.1387 /$ ijdb.1134381f

\title{
Lack of organ specific commitment of vagal neural crest cell derivatives as shown by back-transplantation of GFP chicken tissues
}

\author{
LUCY J. FREEM, JEAN MARIE DELALANDE, ALISON M. CAMPBELL, \\ NIKHIL THAPAR and ALAN J. BURNS* \\ Neural Development and Gastroenterology Units, UCL Institute of Child Health, London, UK
}

\begin{abstract}
Neural crest cells (NCC) are multipotent progenitors that migrate extensively throughout the developing embryo and generate a diverse range of cell types. Vagal NCC migrate from the hindbrain into the foregut and from there along the gastrointestinal tract to form the enteric nervous system (ENS), the intrinsic innervation of the gut, and into the developing lung buds to form the intrinsic innervation of the lungs. The aim of this study was to determine the developmental potential of vagal NCC that had already colonised the gut or the lungs. We used transgenic chicken embryos that ubiquitously express green fluorescent protein (GFP) to permanently mark and fatemap vagal NCC using intraspecies grafting. This was combined with back-transplantation of gut and lung segments, containing GFP-positive NCC, into the vagal region of a second recipient embryo to determine, using immunohistochemical staining, whether gut or lung NCC are competent of recolonising both these organs, or whether their fate is restricted. Chick ${ }^{\text {GFP }}$-chick intraspecies grafting efficiently labelled NCC within the gut and lung of chick embryos. When segments of embryonic day (E)5.5 pre-umbilical midgut containing GFP-positive NCC were back-transplanted into the vagal region of E1.5 host embryos, the GFP-positive NCC remigrated to colonise both the gut and lungs and differentiated into neurons in stereotypical locations. However, GFP-positive lung NCC did not remigrate when back-transplanted. Our studies suggest that gut NCC are not restricted to colonising only this organ, since upon back-transplantation GFP-positive gut NCC colonised both the gut and the lung.
\end{abstract}

KEY WORDS: neural crest cell, enteric nervous system, lung innervation, GFP chicken

\section{Introduction}

The neural crest comprises a multipotent population of migratory cells that gives rise to a wide range of derivatives throughout the vertebrate embryo. These include bones, cartilage, and connective tissues of the craniofacial skeleton, neurons and glia of the sensory, sympathetic and enteric nervous systems, melanocytes, and certain cells of the endocrine system (Kalcheim and Le Douarin, 1999). The hindbrain (vagal) neural crest, adjacent to somites 1-7, is the origin of the majority of the precursor cells that colonise the gastrointestinal tract and form the enteric nervous system (ENS), the intrinsic innervation of the gut (Le Douarin and Teillet, 1973; Yntema and Hammond, 1954). In order to form the ENS, vagal neural crest cells (NCC) migrate from the dorsal neural tube, accumulate in the caudal branchial arches, enter the pharyngeal region of the gut, and progress rostrocaudally along its length to reach the terminal hindgut at approximately 8.5 days of development in the chicken embryo, 14 days of development in the mouse, and 7 weeks of development in the human (Burns and Le Douarin, 1998; Wallace and Burns, 2005; Young et al., 1998). In the course of ENS development, NCC undergo extensive migration and proliferation, and differentiate into a range of neuronal phenotypes as well as glial cells (for reviews see Burns, 2005; Gershon, 2010; Heanue and Pachnis, 2007; Laranjeira and Pachnis, 2009). In addition to the ENS, vagal NCC also give rise to the intrinsic innervation of the lungs (Burns and Delalande, 2005; Tollet et al., 2001). During

Abbreviations used in this paper: E, embryonic day; ENS, enteric nervous system; GFP, green fluorescent protein; NCC, neural crest cell; ss, somite stage.

\footnotetext{
*Address correspondence to: Alan Burns. Neural Development and Gastroenterology Units, UCL Institute of Child Health, 30 Guilford Street, London WC1N 1EH United Kingdom. Tel: +44-(0)20-7905-2721. Fax: +44-(0)20-7831-4366. e-mail: alan.burns@ucl.ac.uk
} 
embryogenesis, the lungs originate as an outgrowth of the primitive foregut concomitant with the rostro-caudal migration of vagal NCC in this gut region. Our previous studies, using quail-chick interspecies grafting and Wnt1-Cre;R26R-YFP transgenic mouse embryos to specifically label and trace NCC, have shown that a sub-population of these vagal NCC leaves the foregut and migrates tangentially into the primitive lungs where they subsequently form ganglia containing neurons and glia (Burns and Delalande, 2005; Freem et al., 2010). Thus vagal NCC that initially migrate to and within the foregut finally reside in different organs, the gut and the lungs, but differentiate into similar phenotypes in the course of their development. This raises the question of how these apparently similar cells leave the foregut to colonise the lungs: is there a subpopulation of vagal NCC that is committed to colonise the lungs by expressing specific receptors that are activated by tissuespecific signalling cue(s), or do these cells migrate from the gut into the lungs by stochastic movement? Having colonised the gut and lung, does the fate of these NCC then become further restricted?

Here, we aimed to test the developmental fate of vagal NCC that had already colonised the gut and the lung by using transgenic chicken embryos that ubiquitously express green fluorescent protein (GFP) (McGrew et al., 2008) to permanently mark and fate-map vagal NCC using intraspecies grafting. This technique, which allows (vagal) NCC to be visualized in live gut and lung tissues, was combined with back-transplantation of gut and lung segments into the vagal region of a second recipient embryo to determine whether NCC that have colonised the gut or lung are committed to re-colonising only their organ of origin, or if they are competent of colonising both the gut and lung.

\section{Results}

\section{Chick $^{G F P}$-chick intraspecies grafting labels neural crest de- rivatives in the gut and the lung}

Intraspecies grafts using chick GFP donors and wild type recipients were performed at E1.5 (Fig. 1) and embryos and tissues harvested up to E8.5. At E3.5, two days after grafts were performed, serial transverse cryosections of chimeric embryos revealed that numerous GFP + NCC had migrated away from the transplanted GFP + neural tube and accumulated around the dorsal aorta and foregut (Fig. 2A). Some of these cells had entered the foregut and occasional GFP + cells were present within the primitive lung buds (Fig. 2B). Further along the gut, numerous NCC were present within the stomach, and in the pre-umbilical intestine (Fig. 2 C,D). Very occasional GFP + NCC were present rostral to the level of the umbilicus (yolk stalk) indicating that the migration wavefront of rostrocaudally migrating NCC had reached this gut level by E3.5 (not shown). At E5.5, numerous GFP+ NCC were evident within the stomach and intestine of chimeric embryos (Fig. 2E), as well as within the developing lung buds (Fig. 2F). The migration front of NCC had reached the level of the rostral cecum at this stage (Fig. 2G).

In freshly dissected embryos at E7.5 (i.e. unfixed and unstained), after removal of the heart and liver, GFP+ NCC were clearly visible along the gastrointestinal tract, with a distinctive band of NCC encircling the stomach (Fig. 3 A,B). At this stage of development, the migration front of NCC had progressed along the intestine and colonised approximately $75 \%$ of the colorectum, with only the terminal part of the gut remaining uncolonised (Fig. 3
B-D). Numerous GFP + NCC were also apparent within the lungs, forming chains of interconnected cells (Fig. 3 E,F).

When intact lungs from chimeric embryos were examined in wholemount preparations, it was evident that the lungs increased in size from E5.5 to E8.5 and that the number of GFP+ cells present within the lungs markedly increased over this period of time (Fig. 4). At E5.5, GFP+ NCC were present within the lungs as chains of cells that formed a diffuse interconnected network extending along the lung (Fig. 4C), and from E7.5 distinct groupings of cells, similar to ganglia within the plexuses of the gut, were apparent (Fig. 4 I,L). These ganglia were distributed extensively throughout the lung at E8.5, and interconnected strands of GFP+ cells extended from the ganglia towards the lung periphery (Fig. 4L).

\section{Back-transplanted GFP+ gut neural crest cells (NCC) remi- grate and colonise the gut and lung}

Vagal GFP + grafts were initially carried out at E1.5, and embryos harvested at E5.5-E6.5, when GFP+ NCC had migrated extensively and were present within the gut and lungs. Tissues from these stages were used for back-transplantation experiments. Segments of E5.5 pre-umbilical midgut containing GFP+ NCC were back-transplanted into the vagal region of E1.5 embryos (Fig. 1) and allowed to develop for up to a further 7 days. When E7.5
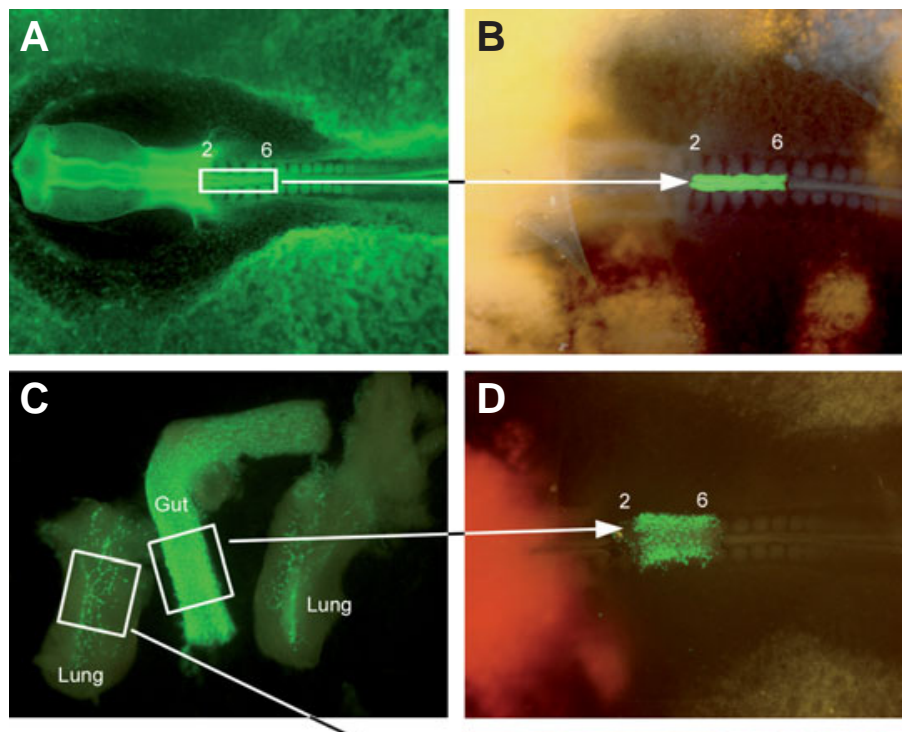

Fig. 1. Protocols for chick ${ }^{\mathrm{GPP}}$-chick intraspecies grafts and backtransplantations of gut and lung tissues. (A,B) For vagal neural tube grafts, the neural tube, adjacent to somites 2-6 inclusive was removed from a chick ${ }^{G F P}$ embryo (A) at 1.5 of development (10-12 somite stage) and transplanted into the vagal region (between somites 2-6) of

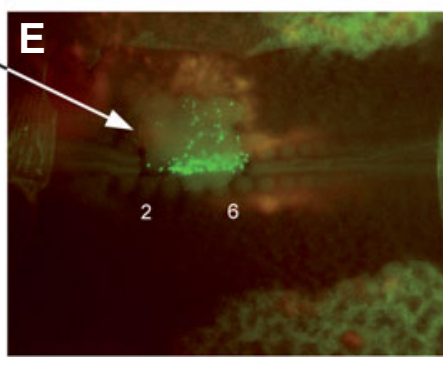
a normal chick embryo (B) at an equivalent stage of development. The transplanted GFP+ neural tube is clearly visible ( $B$, green fluorescence). Vagal grafted embryos were harvested at E5.5-E6.5 and the gut and lungs removed. Segments of gut and lung were dissected (C) and transplanted into 10-12 somite stage normal chick embryos in which the neural tube, adjacent to somites 2-6, had been ablated. The gut (D) and lung (E) tissues containing GFP+cells were pushed into the region of the ablated neural tube. 
embryos that had received back-transplanted gut were examined (Fig. 5), GFP + NCC were found within the gut and in the lungs ( $n=3$ from 5 survivors out of a total of 11 gut back-transplants), with a distribution similar to that exhibited by embryos that had received a vagal GFP graft (i.e. as in Fig. 3). A distinctive band of NCC encircled the stomach (Fig. 5 A,B) and NCC were present within the intestine. It was notable that the GFP+ NCC network
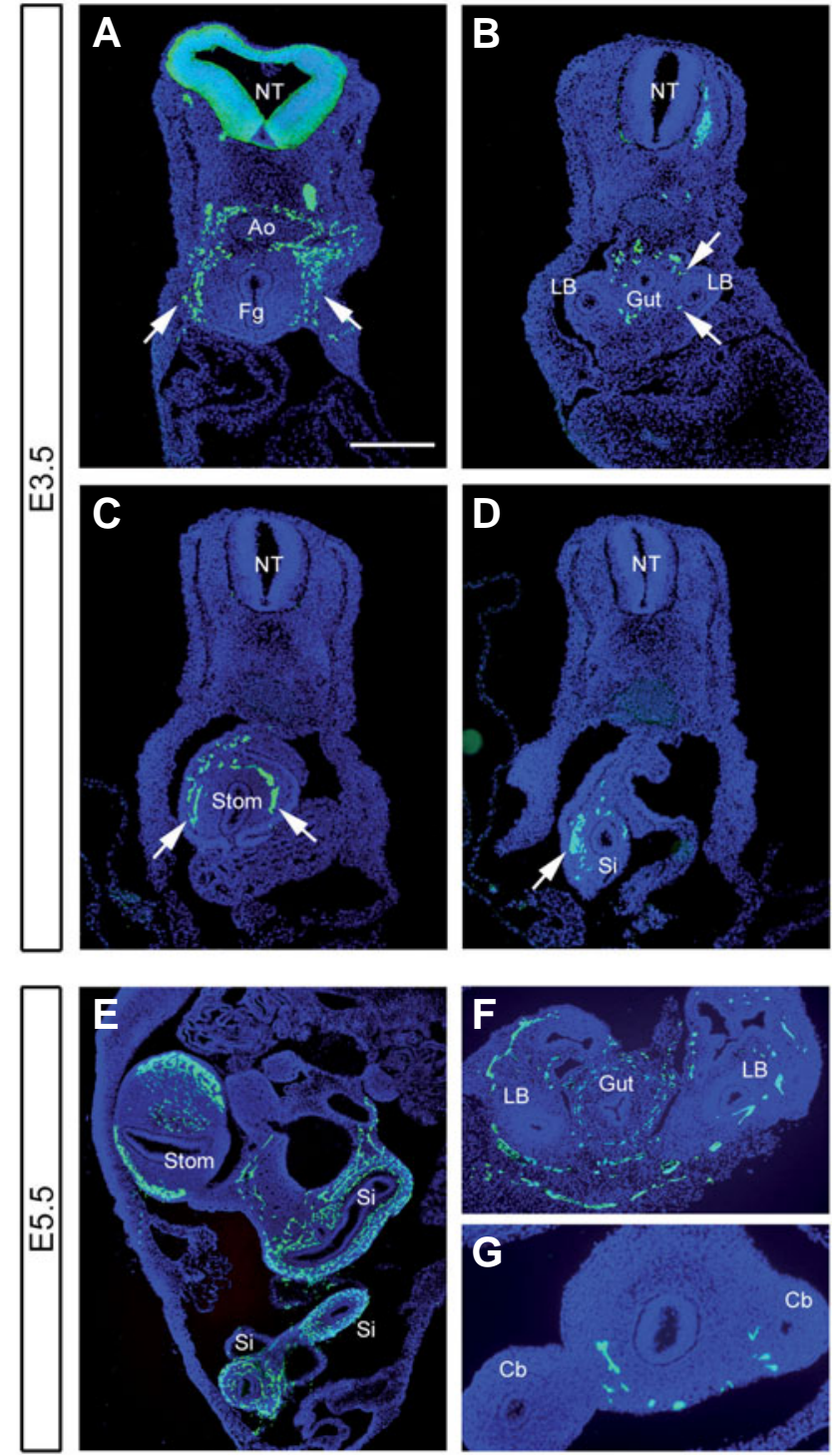
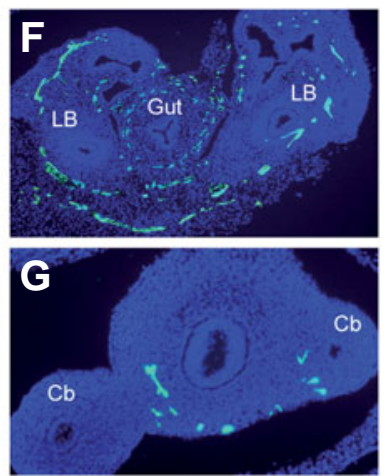

within the myenteric plexus layer of the intestine appeared less dense in the back-transplanted embryos compared to vagal grafted embryos (compare Fig. $3 \mathrm{C}$ with Fig. $5 \mathrm{C}$ ). Also the migration front of NCC had not progressed as far along the gut, and had only reached the caudal level of the cecal buds, whereas in control vagal grafted embryos the migration front approached the terminal gut. In the back-transplanted embryos GFP+ NCC at the migration front were also sparser, had fewer interconnections, and were frequently spindle-shaper and separated from neighbouring cells (Fig. 5D). However, GFP+ NCC were numerous within the lungs (Fig. $5 \mathrm{~A}, \mathrm{E}, \mathrm{F}$ ) and they occurred in a similar distribution and density to NCC within the lungs of vagal-grafted embryos (compare Fig. 3F with Fig. 5F), forming characteristic interconnected chains of cells (Fig. 5F).

When gut and lungs were double immunostained with GFP and the early neural marker TuJ1, to determine whether backtransplanted gut GFP+ cells differentiated into neurons, similar

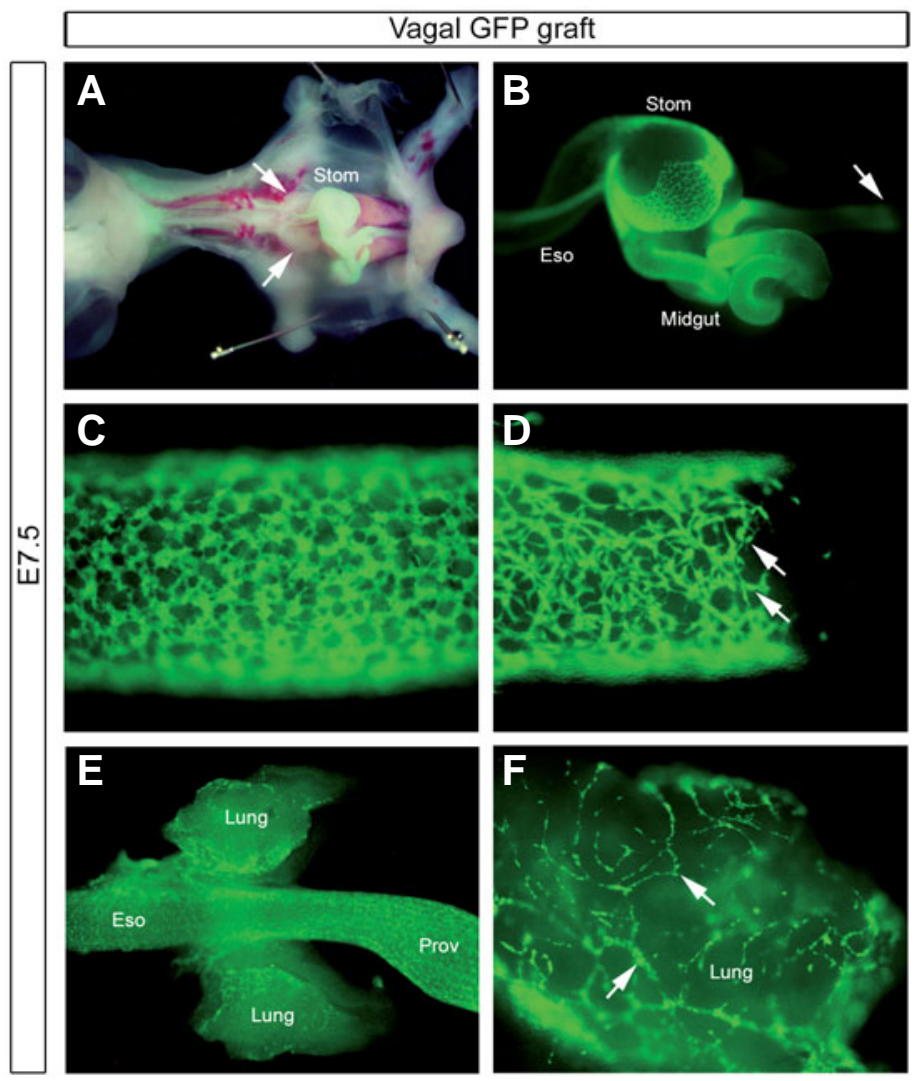

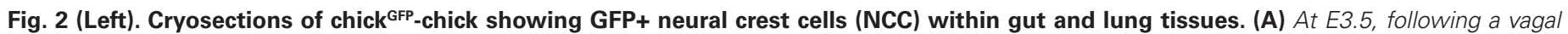
neural tube graft, the neural tube is GFP+ and NCC (arrows) are apparent encircling the aorta (Ao) and the foregut. (B) Occasional NCC (arrows) are present within the primitive lung buds. (C,D) GFP+ NCC (arrows) are located in the outer layers of the stomach and small intestine respectively. (E) At E5.5 numerous NCC are present within the stomach and the loops of the small intestine. (F) NCC encircle the gut at the level of the presumptive myenteric plexus, and interconnected strands of GFP+ cells are present within the lung buds. (G) The migration front, evident as occasional GFP+ cells, is at the level of the cecal buds. NT, neural tube; Ao, aorta; Fg, foregut; LB, lung buds; Stom, stomach; Si, small intestine; Cb, cecal buds. Scale bar, $250 \mu \mathrm{m}$ in $(A-D, F) ; 500 \mu \mathrm{m}$ in (E); $125 \mu \mathrm{m}$ in (G).

Fig. 3 (Right). E7.5 wholemount preparations of chick embryo and dissected gut and lungs following chick ${ }^{\text {GFP }}$ vagal neural tube grafting. (A) After removal of the heart and liver GFP+ NCC are visible along the majority of the gastrointestinal tract. The lung buds are highlighted (arrows). (B) GFP+ cells form an intricate network within the stomach. The migration front of NCC (arrow) has reached the rostral hindgut. (C) Within the midgut, GFP+ NCC coalesce as groups of cells at the level of the myenteric plexus. (D) At the migration front, GFP+ NCC (arrows) are highly interconnected with neighbouring cells. (E,F) GFP+ NCC are located within the lungs and consist of chains of cells that form a diffuse interconnected network (arrows). Stom, stomach; Eso, esophagus; Prov, proventriculus. 
patterns of immunostaining were observed in gut and lung tissues that had received back-transplanted gut segments, compared with gut and lung tissues from control vagal grafted embryos (Fig. 6). TuJ1 immunostaining revealed the characteristic pattern of intrinsic innervation of the stomach (Fig. 6 A,G) and TuJ1+ nerve fibres and cell bodies were stereotypically arranged at the level of the myenteric plexus within the midgut (Fig. $6 \mathrm{~B}, \mathrm{C}, \mathrm{H}, \mathrm{I}$ ). However, there appeared to be more Tuj1+/GFP-ve cells within the myenteric plexus of embryos that received back-transplanted gut segments compared with gut from embryos that received a GFP vagal graft (compare Fig. 6H with Fig. 6B). Within the lungs of control embryos (Fig. $6 \mathrm{D}-\mathrm{F}$ ) and embryos that had received back-transplanted gut segments (Fig. $6 \mathrm{~J}$-L) GFP+ NCC occurred in close association with TuJ1 + nerve fibres that projected throughout the lung forming a diffuse interconnected network. Thus, these findings demonstrate that when GFP + gut NCC are back-transplanted into the early migration pathway, these cells remigrate to colonise the gut and lung, and differentiate into neurons in appropriate locations.

\section{Back-transplanted GFP+ lung NCC do not remigrate within recipient embryos}

When segments of lung from E5.5 and E6.5 embryos that had received a vagal GFP graft were back-transplanted into E1.5 embryos (Fig. 1) and harvested at E7.5, GFP + NCC were not observed in the gut or lungs of the back-transplanted embryos $(n=18)$. When sections were made through the vagal region of these embryos at the site of back-transplantation, GFP+ cells could still be observed within the transplanted lung tissue, but they did not appear to have migrated far from the graft site, and only very occasional $\mathrm{GFP}+$ cells were present within a maximum of approximately $200 \mu \mathrm{m}$ from the lung tissue (Fig. 7 A,B). This finding is in contrast with embryos that received back-transplanted gut segments, as in these experiments numerous GFP+ cells migrated extensively away from the back-transplantation site by E7.5 (Fig. 7 C,D).

In order to address why GFP+ lung NCC do not remigrate in back-transplant experiments, instead of transplanting segments of lung tissue containing relatively few GFP+NCC, we transplanted $\mathrm{GFP}+$ cells that were isolated by fluorescence-activated cell sorting (FACS) and cultured to form aggregates. These aggregates, that contained only GFP+ NCC, were then transplanted into the ablated neural tube region of $\mathrm{E} 1.5$ wild Vag, vagus nerve. type host embryos (not shown). However, using this approach, $\mathrm{GFP}+$ cells, obtained from either lung or gut, did not migrate away from aggregates and GFP + cells were not observed in the gut or the lungs of any of the recipient embryos $(n=13)$. Thus, in all experiments that were performed with back-transplanted lung tissues or aggregates of GFP + cells derived from lungs or from gut, there was no significant migration of back-transplanted NCC, neither away from the graft site, nor to the gut or lungs.

A possible explanation for this failure of lung NCC to remigrate is that there are insufficient NCC numbers in back-transplanted lung tissues compared with back-transplanted gut and/or that the neural crest-derived cells within the lung have already differentiated at the time of back-transplant. To address these possibilities, quantitative studies, using immunohistochemistry and confocal microscopy, were carried out. Results demonstrated that the num-
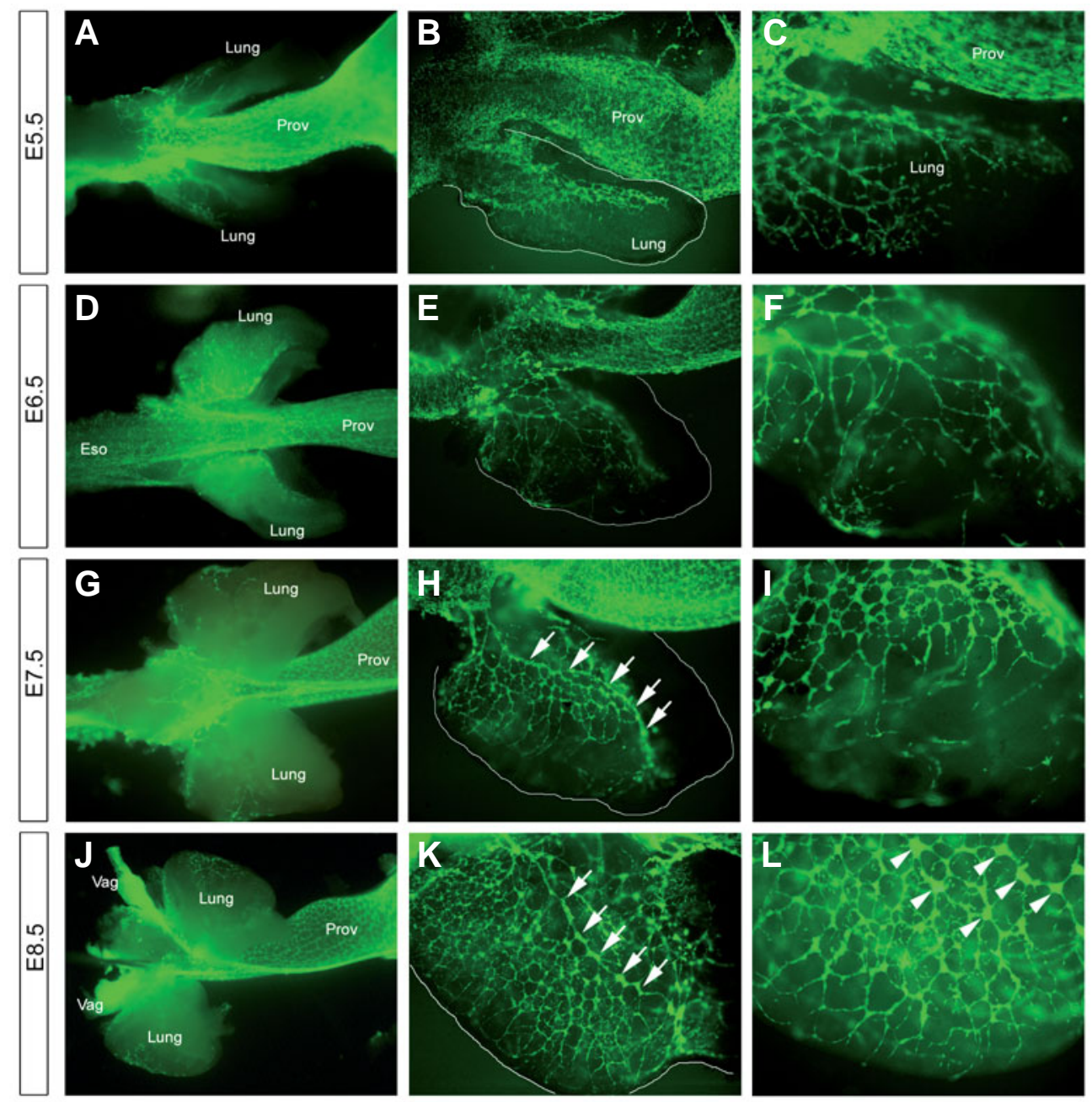

Fig. 4. Wholemount preparations of foregut and lungs from chick embryos that received a vagal GFP graft. (A-C) At E5.5 numerous GFP+NCC are apparent within the proventriculus region of the foregut. GFP+ strands of cells extend into the lungs (marked with white line) where they begin to form an interconnected network (C). At E6.5, (D-F) the network of GFP+NCC within the lungs is more extensive, and by E7.5 (G-I) an interconnected chain of GFP+ runs along the length of the lung (H, arrows), with progressively finer GFP+ projections extending towards the periphery. At E8.5 (J-L), numerous GFP+ cells and interconnected ganglia (see arrows in (K)) are present within the lung. High magnification reveals interconnected GFP+ ganglia (see arrowheads in (L)). Prov, proventriculus; Eso, esophagus, 


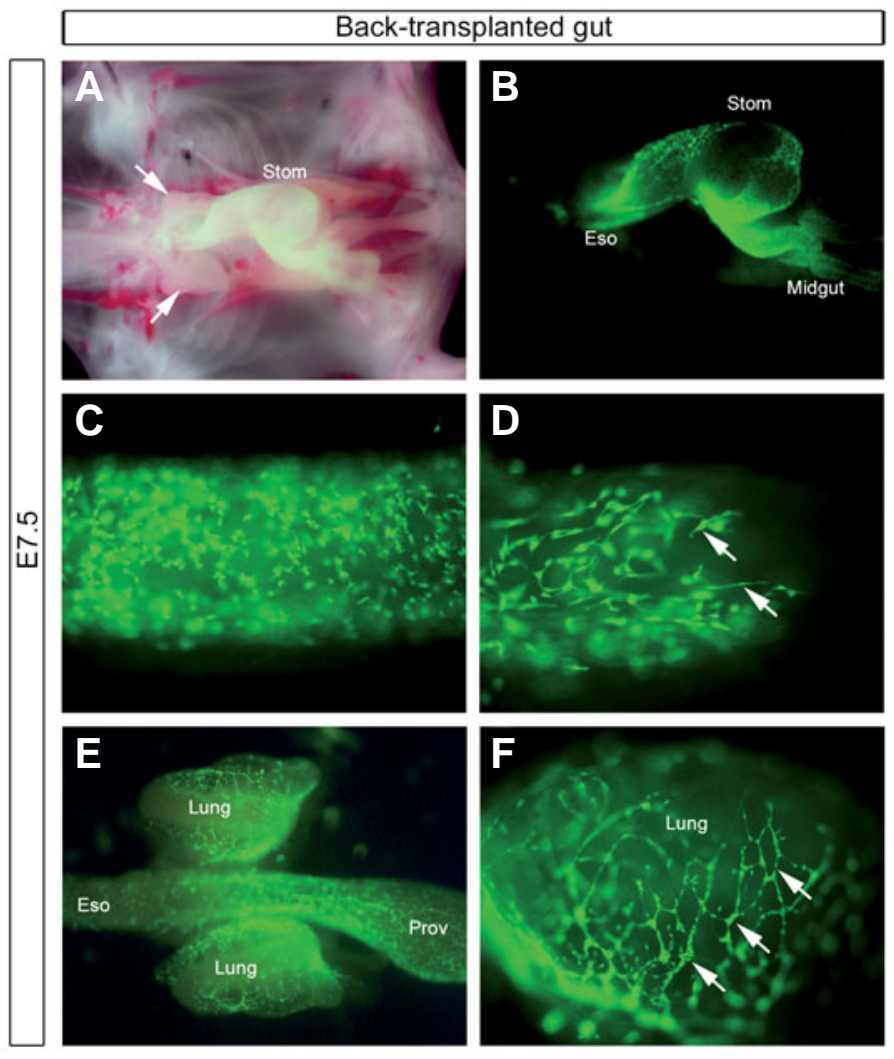

Fig. 5. E7.5 wholemount preparations of chick embryo and dissected gut and lungs following back-transplantation of gut segments containing GFP+ neural crest cells (NCC). (A) After removal of the heart and liver GFP + NCC are visible along the majority of the gastrointestinal tract. The lung buds are highlighted (arrows). (B) GFP+ cells form an intricate network within the stomach and throughout the midgut. (C) Scattered GFP+ NCC are present at the level of the myenteric plexus. (D) At the migration front, spindle-shaped GFP+ NCC (arrows) are often not interconnected with neighbouring cells. (E,F) GFP+NCC are located within the lungs and consist of chains of cells that form a diffuse interconnected network (arrows). Stom, stomach; Eso, esophagus; Prov, proventriculus.

ber of GFP + NCC within the most highly colonised region of the lungs is over eight fold less than the number of GFP+ NCC within the midgut (per unit volume) at time of back-transplantation (Fig. $8 \mathrm{~A})$. Further, in donor lung tissue, the few GFP+NCC that were present were always associated with TuJ1+ neural tissue (Fig. 8 $\mathrm{B}, \mathrm{C})$, whereas in the donor gut, although numerous GFP + NCC were associated with the TuJ1+ network of the myenteric plexus (Fig. $8 \mathrm{D}, \mathrm{E}$ ), there were also many GFP+cells in the as yet undifferentiated (Tuj1 negative) submucosal plexus region (Fig. 8E).

\section{Examination of lung innervation in DCC mutant mice}

Our current and previous studies suggest that vagal NCC undergo tangential migration from the gut into the lungs. Other studies have reported similar tangential migration of NCC from the gut into organs such as the pancreas, and have implicated the Netrin/DCC pathway in the attraction of DCC-expressing NCC by netrins (Jiang et al., 2003). To determine whether Netrin/ DCC signalling is involved in NCC colonisation of the lung, we analysed $D C C^{-/}$mouse embryos at a stage of development when NCC have been shown to be present within the lung in significant numbers (Freem et al., 2010). Cryosections of $D C C^{+/+}$(Fig. 9 $A-C)$ and $D C C^{-/}$(Fig. 9 D-F), littermate E14.5 mouse embryos, immunostained with TuJ1, revealed neural tissue, apparent as ganglia and fine calibre nerve fibres, in equivalent amounts in lungs of both genotypes. Thus these studies suggest that Netrin/ DCC signalling is not necessary for lung NCC development.

\section{Discussion}

The neurons and glial cells that comprise the intrinsic innervation of the lung and of the gut have a common vagal neural crest developmental origin and they share the same early migratory pathways to and within the foregut (Burns and Delalande, 2005; Burns et al., 2008; Freem et al., 2010). It is therefore reasonable to hypothesise that these NCC may respond to common signalling pathways, at least early in development, but that within this population some NCC may be committed, by expression of specific receptors or signalling pathway components, to subsequently colonise either the gut or the lungs. In order to gain insight as to whether lung and gut NCC are committed to migrate into their respective target organs, we performed a series of neural crest transplantation experiments in the chick embryo. We carried out intraspecies grafting using donor tissue from GFP transgenic chicks to permanently label and fate-map NCC within wild-type chick hosts. Using a microsurgical approach similar to that employed for quail-chick grafting (Barlow et al., 2008; Burns, 2005; Burns and Le Douarin, 1998) the vagal neural tube and associated neural crest from GFP chick embryos was transplanted into wild-type recipients. We found that the grafted GFP+ neural tube integrated into the host embryo and GFP + NCC migrated extensively along previously described stereotypical pathways to colonise the gut and lung buds (Burns and Delalande, 2005; Burns and Le Douarin, 1998; Burns and Le Douarin, 2001). Thus chick ${ }^{\mathrm{GFP}}$-chick intraspecies grafting is an efficient and reliable way of tracing NCC migration and development and represents an important technical advance over the extensively used and informative quail-chick grafting technique established by Le Douarin in the late 1960s (Kalcheim and Le Douarin, 1999; Le Douarin, 1969). Advantages of chick ${ }^{\text {GFP }}$-chick intraspecies grafting over quail-chick grafting include: (i) Under fluorescent light, GFP fluorescence is extremely bright and intense, and GFP+ cells are easily discernable in live chimeric recipients even without immunostaining for GFP. This allows the success of the graft to be checked in ovo, whereas quail-chick grafting requires the embryo to be killed, chemically fixed and immunostained with the quail cell-specific marker, QCPN, before the success of the graft can be ascertained (Teillet et al., 2008). (ii) GFP chick grafting makes back-grafting of NCC easier, as GFP + NCC in live grafted tissue can be examined and their numbers checked before back-transplanting the tissue into a host embryo. (iii) GFP expression in the transgenic chick line is cytoplasmic and therefore marks the entire cell, allowing cell bodies and projections to be seen (Barraud et al., 2010). This permits intricate neuronal networks to be visualised that are not apparent when using quail-chick grafting, as QCPN marks only the quail cell nucleus. (iv) Intraspecies grafting eliminates any species differences that could potentially be present between grafted quail tissues and chick recipient embryos, since quail embryos have a shorter incubation period than the chick (19 days versus 21 days). Chick GFP-chick grafting therefore represents a significant technical advance and opens the door to further in vivo studies and other 

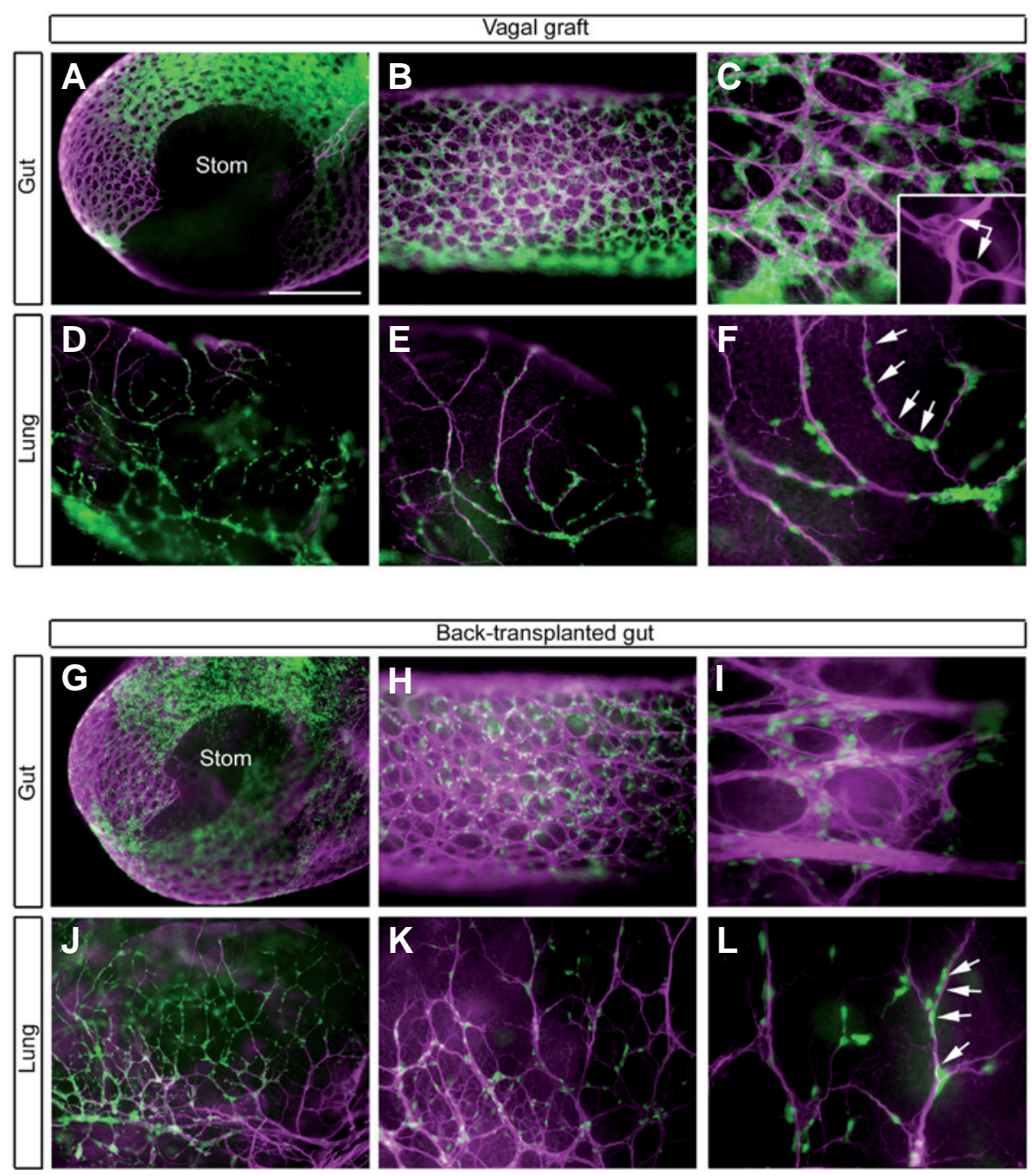

Fig. 6. Wholemount preparations of gut and lungs from E7.5 chick embryos. (A-F) Following grafting of GFP+ vagal neural tube, typical enteric plexuses are labelled within the stomach (A), and the midgut $(\mathbf{B}, \mathbf{C})$, where individual TuJ1+ cell bodies are apparent $(C$, inset, arrows - TuJ1 labelling only, GFP not shown). Within the lungs, (D-F) small groups or individual GFP+ cells (arrows) occur along fine TuJ1+ nerve fibres that extend throughout the lung. Similar patterns of TuJ1/GFP immunostaining are present in the gut (G-I) and lungs (J-L) of embryos that received segments of back-transplanted gut containing GFP+ NCC. Double labelling is with GFP (green) and the neural marker TuJ1 (magenta). Scale bar, $800 \mu \mathrm{m}(A) ; 400 \mu \mathrm{m}(D) ; 200 \mu \mathrm{m}$ (B,E); $100 \mu \mathrm{m}$ $(C, F)$; applies to equivalent panels (G-L).

techniques useful for NCC developmental biology including cell sorting based on GFP fluorescence, organotypic culture of tissues containing GFP + cells, and live imaging of transplanted GFP+ cells.

The aim of this study was to determine the developmental potential of vagal NCC that had already colonised the gut or the lungs. This was addressed by back-transplanting segments of gut or lung containing GFP + NCC that had already migrated into these tissues from the vagal neural crest (Fig. 1). Similar back-transplants have been carried out with segments of quail gut that were back-grafted to the trunk (Rothman et al., 1990), and to the vagal and sacral regions of early chick embryos (Rothman et al., 1993). These previous studies were performed to evaluate the developmental potential of crest-derived cells at the time they colonize the gut but they did not comment on or address NCC colonisation of the lung. However, these studies did show that NCC that have colonized the bowel remain capable of re-migrating and following defined neural crest migration pathways to the gut (Rothman et al., 1993) and to other parts of the autonomic nervous system (Rothman et al., 1990; Rothman et al., 1993) in the host embryo, their destination being dependent on the axial level into which the graft was placed.

In our current study, a number of possible scenarios could arise following back-transplantation of gut and lung NCC into the vagal region of the neural tube. For example, NCC that had already colonised the lung or gut would remigrate only to their original targets indicating that they are committed to selectively colonise these organs. Alternatively, lung or gut NCC would remigrate into both lung and gut regardless of their origin indicating their lack of organ-specific commitment (Fig. 10). In our experiments, we found the latter to be the case, at least for gut NCC. When gut segments containing GFP + NCC were back-transplanted into the vagal region of early embryos, the GFP+ NCC migrated into both the lungs and the gut of the recipient chick embryos (Fig. 5). Although both organs were extensively colonised by back-transplanted NCC, in comparison with control embryos (i.e. those that received a vagal GFP graft), the migration front of NCC was slightly delayed in its progression along the gut, GFP + NCC at the migration front were sparser in number, spindle shaped, and had fewer interconnections, and the GFP+ network along the gut appeared to be less dense. Interestingly this description of aberrant cells at the migration front, and disrupted ENS networks, is similar to that previously reported in the gut when NCC numbers were reduced by ablating part of the vagal neural crest (Barlow et al., 2008). In this previous study, NCC numbers were reduced to such an extent that the migration front halted in the duodenum, whereas in the current study it appears that the back-transplanted gut segments contain sufficient numbers of NCC to allow the gut to be colonised along its length with only more subtle defects occurring. In contrast to the

subtle ENS defects, no differences in the extent of colonisation of the lungs was apparent between control embryos and those that received back-transplants of gut segments containing GFP+ cells. This finding supports the idea that the more rostral tissues (foregut and lungs) are less susceptible to decrease in NCC numbers compared to midgut and hindgut which lack ENS when NCC numbers are reduced experimentally (Barlow et al., 2008; Burns et al., 2000; Peters-van der Sanden et al., 1993), or in mouse models of gut aganglionosis (e.g. Ret pathway mutants, EdnrB/Edn3 mutants: reviewed in Heanue and Pachnis, 2007) where the foregut appears to be normally innervated but variable lengths of the midgut and hindgut, or only hindgut fail to be colonised by NCC. Another possible explanation for the decreased numbers of GFP+ NCC within the Tuj1+ ENS network of embryos that received segments of back-transplanted gut, compared to controls, concerns the tim- 
ing/extent of the grafts. If the GFP graft was performed at the 12 somite stage of development (as some were), and/or comprised neural tube adjacent to somites 3-6, then some early vagal NCC, and NCC from adjacent to somites 1 and 7, would already have entered into the migration pathway and ended up in the ENS as TuJ1+/GFP-ve cells.

Although gut GFP + NCC consistently remigrated and colonised the gut and lung when back-transplanted into early embryos, in our studies GFP + cells never remigrated from back-transplanted lung tissues. Sections through transplanted lung segments showed that GFP + NCC remained close to the graft site and therefore never reached the foregut or lungs. Experiments were performed with donor lung of various stages in an effort to transplant GFP + cells that were still early in their development and potentially more amenable to migration. However, these early lungs (at approximately E5.5) contained few GFP+ cells, and although later stages (E6-6.5), that contained increased numbers of GFP + cells were also used, they did not migrate from these tissues either. In a further effort to augment the number of lung GFP + cells that were back-transplanted, we isolated GFP + cells from lung tissues using FACS and cultured them as hanging drops to produce aggregates of GFP+ cells. However, GFP + cells within transplanted aggregates also failed to migrate from the graft site even when aggregates were formed from gut GFP + cells. It is not clear why lung NCC did not remigrate in any of these studies, but this could be due to the relatively small number of NCC that are present within the lung compared to the gut (see Fig. 1C, Fig. 8), or to terminal differentiation of these cells. Our confocal microscopy studies demonstrated that at the time of back-transplant, most lung GFP+ cells are either co-expressing the neural marker TuJ1, or are closely associated with TuJ1+
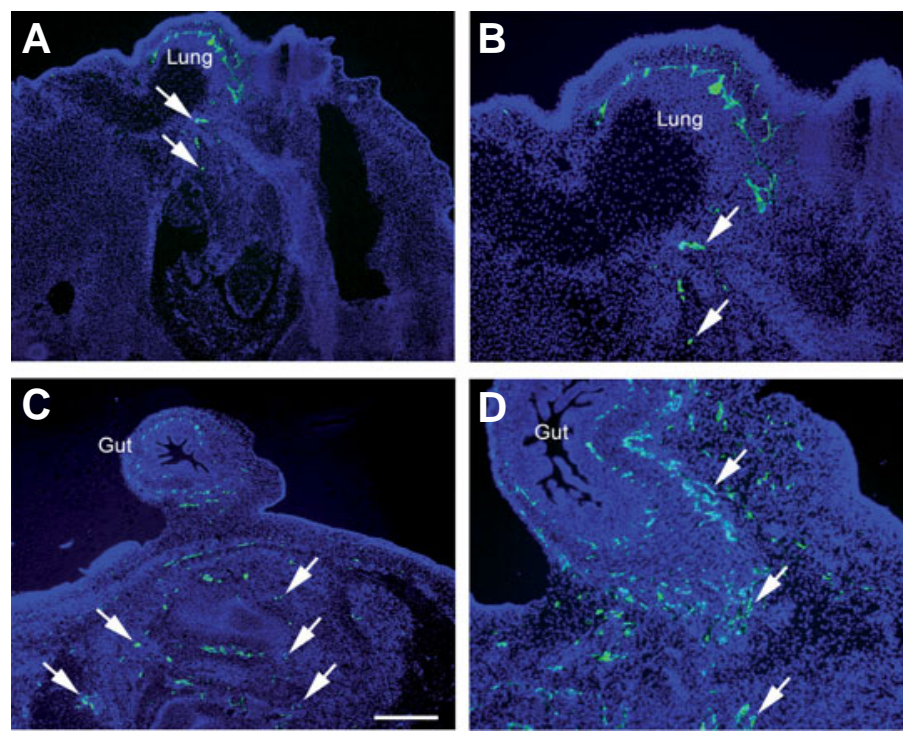

nerve fibres, whereas in the gut, although GFP+ NCC within the myenteric plexus are often associated with TuJ1 immunostaining, the submucosal plexus contains mostly undifferentiated GFP+ cells. Thus the lung appears to contain fewer neural crest-derived cells, the majority of which have already differentiated, compared to the gut that contains not only many more NCC overall, but NCC that are undifferentiated and are therefore more likely to have the ability to remigrate. Another related possibility for the failure of lung NCC to re-migrate is that specific receptors or signalling pathways necessary for migration are downregulated once NCC colonise the lung. However, this does not appear to be the case, at least for NCC that enter the foregut, as we previously demonstrated that genes necessary for early gut colonisation, such as Sox10, Ret, Gfra1 and Ednrb, are expressed within NCC in the gut as well as in the lung at stages when lung back-transplants were performed (Burns and Delalande, 2005). Further, the finding that back-transplanted gut NCC re-migrate and colonise both the gut and lung suggests that

A Mean number of GFP + NCC in the lungs and midgut at E6
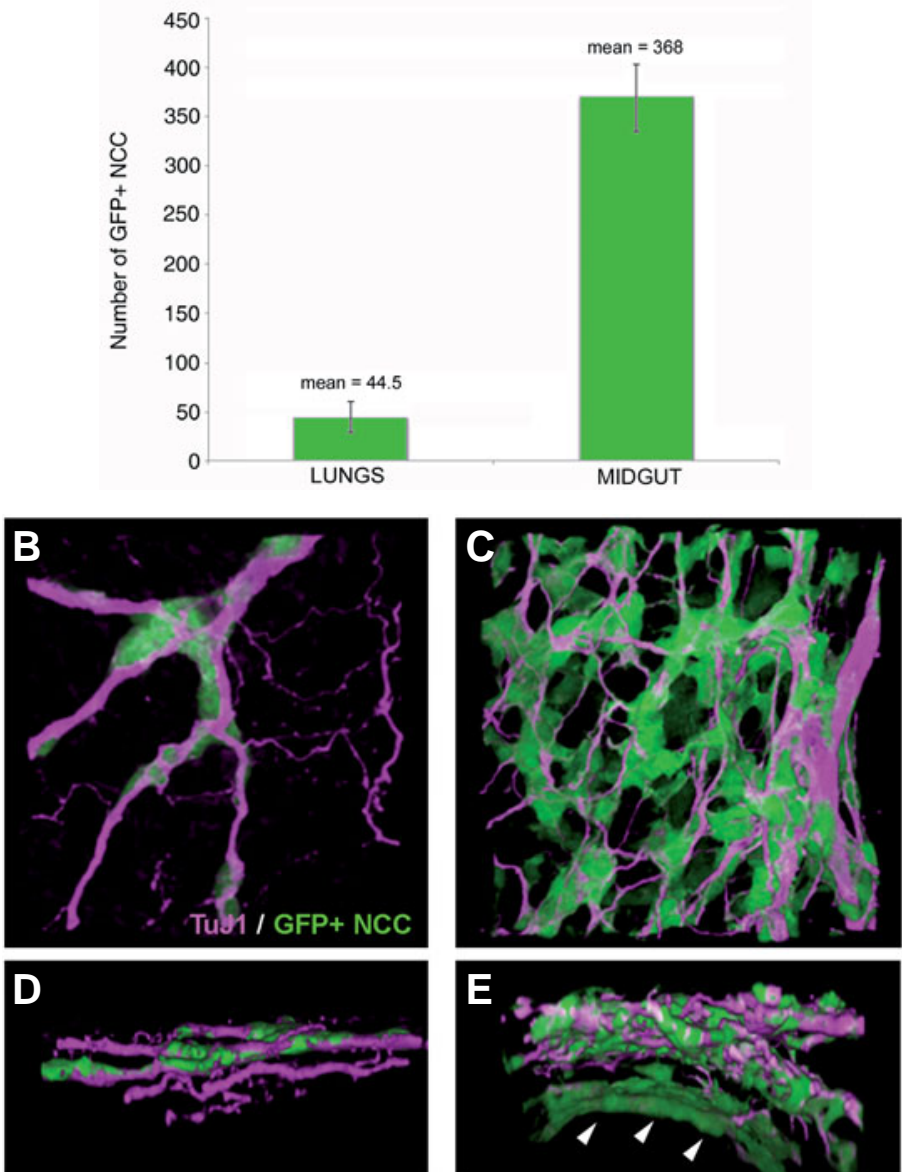

Fig. 7 (Left). Cryosections of E7.5 chick embryos following back-transplantation of lung or gut segments containing GFP+ neural crest cells (NCC) at E1.5. (A,B) GFP+ staining is apparent within transplanted lung, but only very occasional cells (arrows) have migrated from the site of lung transplant into the recipient embryo. (C,D) Following gut back-transplant, GFP+ cells and nerve fibres (arrows) are present within the gut tissue, and within the recipient embryo, distant from the site of transplant. Scale bar, $100 \mu \mathrm{m}(A, C) ; 50 \mu \mathrm{m}(B, D)$.

Fig. 8 (Right). Quantification of the number of GFP+ neural crest cells (NCC) in representative E6 lung and midgut tissue samples used for back-transplantation experiments. (A) Histogram showing the number of GFP+NCC in lung and midgut, counted in areas of equal volume $(134 \times 134 \times 50 \mu \mathrm{m})$. (B-E) Representative lung and midgut projection confocal images of the area used for cell counting showing TuJ1 (magenta) and GFP (green) immunostaining. $(B, D)$ dorsal view; $(C, E)$ lateral view. Arrowheads point to TuJ1 negative/GFP+ NCC in the submucosal plexus. 
specific receptors or signalling pathways necessary for migration are not downregulated when these cells originally colonise the gut, although a more extensive molecular analysis of NCC within the gut and in the lung at various time points remains to be performed.

NCC are multipotent precursors that migrate extensively throughout the embryo and subsequently generate a wide range of phenotypes. Because of this generation of morphological diversity from apparently homogeneous cell populations, NCC have received much attention as a developmental model and various ideas have been put forward to explain their morphogenesis: (i) NCC differentiate at target sites according to cues encountered in the local environment, (ii) NCC become restricted to particular fates early in development and migrate along particular pathways due to cell-autonomous properties, (iii) NCC behave due to a combination of the above. Extensive evidence supports the idea that certain NCC lineages are specified to particular fates (reviewed in Harris and Erickson, 2007; Kuo and Erickson, 2010; Ruhrberg and Schwarz, 2010), and even within the vagal neural crest, cells from different sub-levels have different contributions: we have previously shown that different axial levels of vagal crest contribute cells to various gut regions (Burns et al., 2000), and recently Kuo and Erickson have demonstrated that anterior vagal NCC (somites 1-3) show considerable migratory plasticity, whereas posterior vagal NCC (somites 5-7) are more restricted in their behaviour (Kuo and Erickson, 2011). From these findings, these authors suggest that the vagal region represents a transition between cranial and trunk neural crest.

We have also previously demonstrated that vagal and sacral NCC have intrinsic differences in their ability to colonize the gut, and/or to respond to signalling cues within the gut environment (Delalande et al., 2008). In this previous study, using gene chip analysis, we found that of a number of key enteric NCC development genes, Ret was expressed fourfold higher in vagal versus sacral NCC and that when Ret was overexpressed in sacral NCC these cells behaved like vagal NCC in terms of their development within the gut. Thus the level of Ret expression influenced the extent to which different NCC populations colonised the gut (Delalande et al., 2008), suggesting some level of specification. Regarding the NCC that colonise the lung, to date we have not found expression

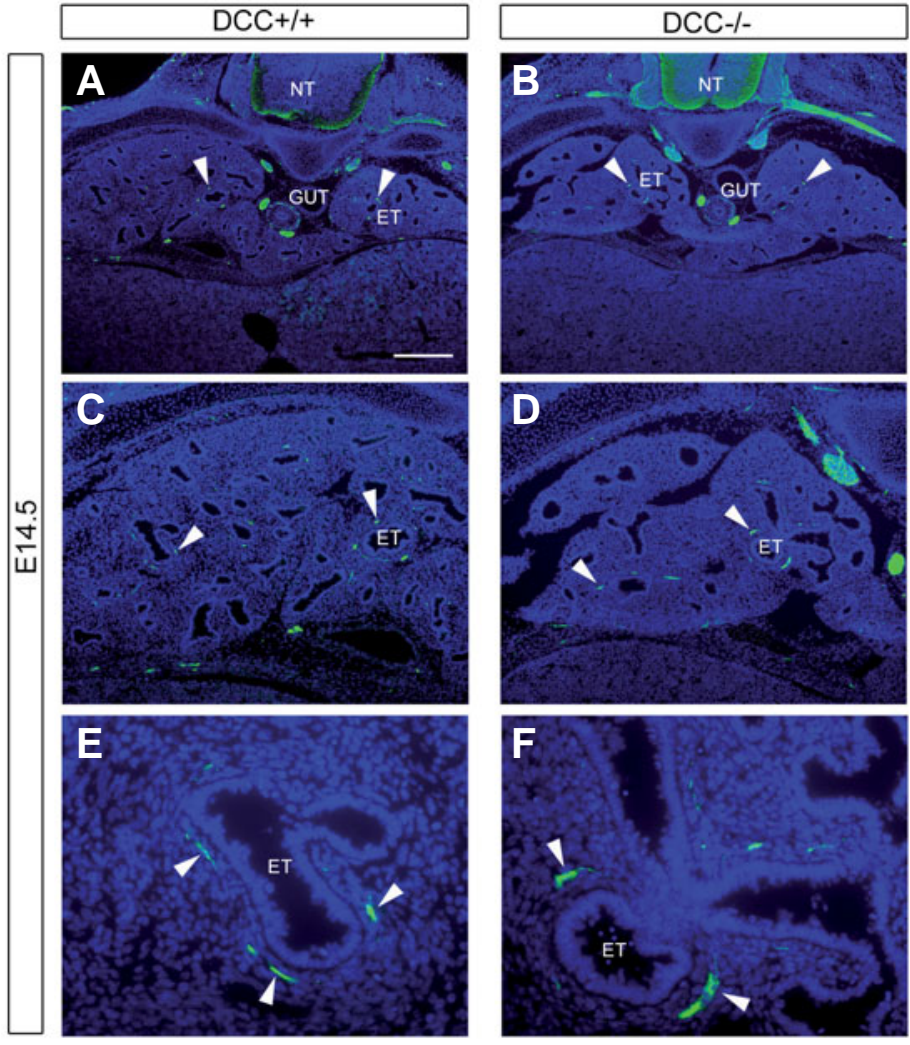

Fig. 9 (Left). Cryosections of $D C C^{+/+}$and $D C C^{/-}$littermate E14.5 mouse embryos, immunostained with the neural markerTuJ1. (A,D) Neural tissue is located surrounding the gut and in the lungs (arrowheads) of both genotypes. Within the lungs of wildtype (B,C) and mutant embryos $(\mathbf{E}, \mathbf{F})$, neural tissue, apparent as ganglia and fine calibre fibres, is in close association with the epithelial tubules as seen in transverse section. NT, neural tube; ET, epithelial tubule. Scale bar, $200 \mu \mathrm{m}(A, D) ; 100 \mu \mathrm{m}(B, E) ; 25 \mu \mathrm{m}(C, F)$.
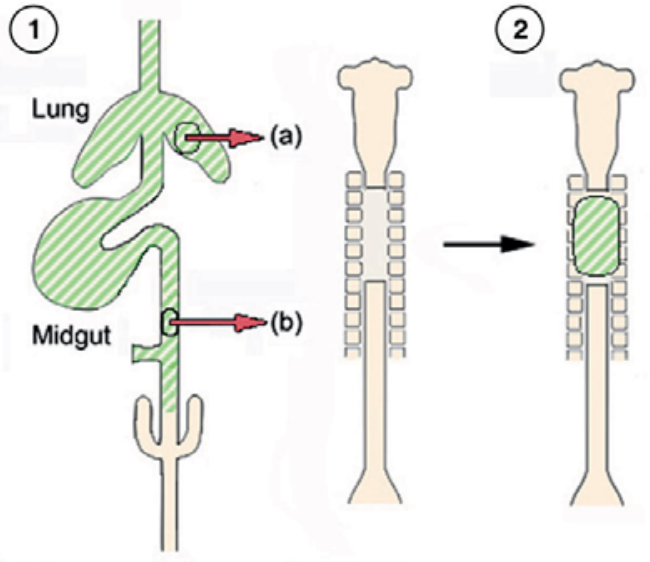

(3)
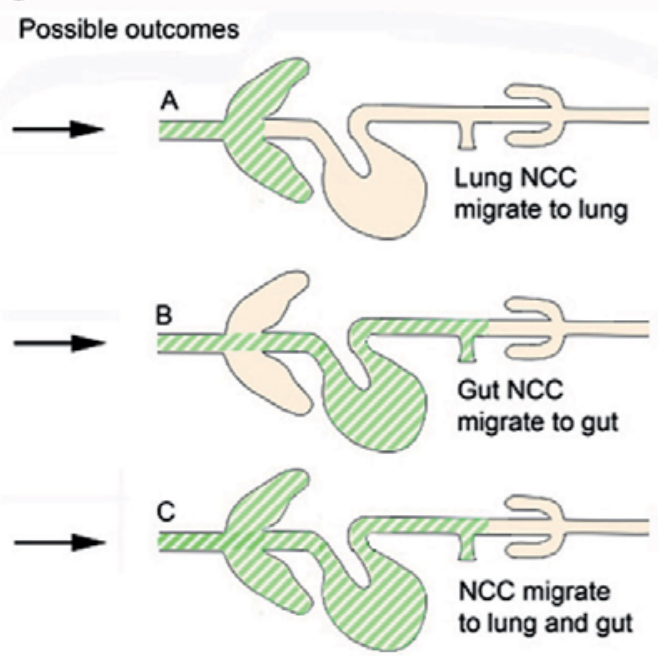

Fig. 10 (Right). Schematic diagram showing possible outcomes of the NCC back-transplantation experiments. (1) Segments of lung (a) or gut (b) from chimeric embryos, containing GFP + NCC (green) are removed from E5.5-6.5 chicks and transplanted into the ablated vagal neural tube region of an E1.5 wild-type chick. (2) The back-transplant recipient chick embryo is allowed to develop up to a further 7 days. (3) The possible outcomes of lung and gut back-transplants are shown. Lung and gut NCC may migrate only to their original sites $(A, B)$ indicating that they are committed to colonise these targets, or they may migrate into both lung and gut regardless of their organ of origin indicating their lack of commitment (C). 
of receptors that are unique to lung NCC (Burns and Delalande, 2005), but our previous study on vagal and sacral NCC suggests that levels of gene expression in NCC, that may include Ret, could be involved in directing cells to leave the gut and colonise the lungs. However, this remains an area for future investigation. Other studies that have examined the tangential migration of NCC from the gut into organs such as the pancreas, have implicated the Netrin/ DCC pathway in the attraction of DCC-expressing NCC by netrins (Jiang et al., 2003). To determine whether Netrin/DCC signalling is involved in NCC colonisation of the lung, we analysed $D C C^{-}$mouse embryos but a deficit in the neural crest-derived intrinsic lung innervation was not apparent compared with littermate controls, thus suggesting that Netrin/DCC signalling is not necessary for lung NCC development. Ongoing studies are examining various mutant mice in an effort to gain insight into the signalling pathways underlying the guidance of NCC from the gut into the lung.

In conclusion, in this study we have utilized chick ${ }^{\text {GFP-chick in- }}$ traspecies grafting to label and fate map NCC within the gut and lung of chick embryos. This technique represents an important technical advance for cell lineage analysis and has a number of advantages over the established quail-chick grafting technique for labelling and tracing the fate of NCC. Our studies showed that vagal NCC, in addition to colonising the gut to form the ENS, extensively colonise the lungs. Using back-transplantation of tissues containing GFP+ NCC we demonstrated that gut NCC are not committed to colonising only this organ, since upon back-transplantation gut NCC were still competent of colonising the gut and the lung and of differentiating into neurons in stereotypical locations. Further studies are required to determine the mechanisms underlying the development of intrinsic lung innervation, and the functional role these neural crest-derived cells play before and after birth, both in health and disease.

\section{Materials and Methods}

\section{Chick $^{\text {GFP }}$-chick intraspecies tissue grafting and back-transplantations}

Fertile chicken eggs, obtained from commercial sources, and transgenic GFP chicken eggs, obtained from The Roslin Institute, The University of Edinburgh (McGrew et al., 2004; McGrew et al., 2008), were incubated at $37, \mathrm{C}$ and staged according to the developmental tables of Hamburger and Hamilton (Hamburger and Hamilton, 1951), or according to the number of pairs of somites formed. For chick ${ }^{\text {GFP }}$-chick grafting, the neural tube and associated neural crest, adjacent to somites 2-6 inclusive, was microsurgically removed from normal chick embryos at the 9-11 somite stage (ss) of development (embryonic day 1.5) and replaced with equivalent tissue obtained from chick ${ }^{\text {GFP }}$ embryos at the same stage of development as previously described for quail-chick grafting (Burns and Le Douarin, 1998). Grafts of this size provided extensive labelling of the ENS combined with good embryo survival. Following grafting, eggs were returned to the incubator, and embryos allowed to develop up to a further 7 days such that GFP+ NCC colonised the gut and lungs.

For back-transplantations, small segments of pre-umbilical midgut or lung containing GFP + NCC were removed from E5.5-6.5 chicks and backtransplanted into the vagal (neural tube ablated) region of a second host chick embryo at E1.5 (Fig. 1). These back-transplanted embryos were returned to the incubator and allowed to develop further until harvesting at E3.5-8.5.

\section{Formation of NCC aggregates for back-transplantation}

As an alternative to transplanting segments of chimeric lung or gut into the vagal region of host embryos, GFP+ NCC from these tissues were isolated, cultured and transplanted as cell aggregates. To obtain aggregates, GFP+ cells were selected using fluorescence-activated cell sorting (FACS). First, lung lobes or gut tissues were minced in phosphate buffered saline (PBS) containing $1 \%$ penicillin/streptomycin (pen/strep) then centrifuged at $1000 \mathrm{rpm}$. The supernatant was removed and the lung or gut tissue resuspended in $2 \mathrm{ml}$ enzyme mix (Collagenase $\mathrm{XI}$, Dispase II, $1 \%$ pen/strep). The tissue was digested in enzyme mix for 20 minutes at $37^{\circ} \mathrm{C}$ then the enzymes were inactivated by the addition of culture medium (DMEM, N2, B27, pen/strep) 1:1 with the existing suspension, and the mixture centrifuged for 5 minutes at $1000 \mathrm{rpm}$. The supernatant was removed and the cell pellet resuspended in $1 \mathrm{ml}$ culture medium, then passed through a $100 \mu \mathrm{m}$ cell strainer. The cells were then centrifuged again and the remaining pellet resuspended in $500 \mathrm{ul}$ medium. The suspension was transferred to FACS tubes and transferred on ice for sorting. Cell sorting was performed using a MoFlo XDP (Beckman Coulter) with Summit software. After FACS, the positive fraction of cells was pelleted by centrifuging for 5 minutes at 1000rpm and resuspended in culture medium. The suspension was then pipetted in $60 \mu \mathrm{l}$ drops that were placed on the underside of the lid of a Petri dish in the form of 'hanging drops'. The lid was placed on a Petri dish filled with $10 \mathrm{ml}$ DMEM, $1 \%$ pen/strep to keep the environment surrounding the droplets humid. The hanging drops were then left overnight at $37^{\circ} \mathrm{C}$. By the next morning GFP+ cells within the drops had formed irregularly shaped aggregates $200-500 \mu \mathrm{m}$ in diameter. These aggregates were transplanted into the ablated vagal neural tube region of E1.5 wild type recipient embryos. The recipient embryos were left to develop for up to a further 6 days before harvesting.

\section{Immunohistochemistry}

For immunolabelling of cryosections, embryos or dissected tissues were fixed in 4\% paraformaldehyde (PFA) for 3-4 hours, cryoprotected in $15 \%$ sucrose in PBS, and prepared as previously described (Barlow et al., 2008). Frozen sections were cut at $12 \mu \mathrm{m}$ using a Leica CM1900 cryostat at $-22^{\circ} \mathrm{C}$. Following blocking in PBS containing $0.1 \%$ Triton- $\mathrm{X}-100,1 \%$ Bovine Serum Albumen and $0.15 \%$ glycine, sections were incubated in primary antibodies diluted in antibody blocking solution overnight at $40 \mathrm{C}$. These included anti-ßIII tubulin (also called TuJ1, from Covance) 1:1000, and anti-GFP (Invitrogen) 1:250. Slides were then washed in PBS and incubated with fluorescently tagged secondary antibodies (either anti-rabbit Alexa Fluor 488, 1:500, or anti-rabbit Alexa Fluor 568, 1:500, Invitrogen) for 1.5 hours at room temperature. Following further washing in PBS the slides were mounted with Vectashield Hard Set containing DAPI (Vector Laboratories) and examined using a Zeiss Axioskop microscope fitted with a Leica DC500 digital colour camera.

For wholemount staining, dissected gastrointestinal tracts with attached lungs were fixed for $1-2$ hours in 4\% PFA in PBS then rinsed 3 times in PBS at room temperature and processed as previously described (Freem et al., 2010). Briefly, antibody blocking solution (10\% sheep serum, $1 \%$ Triton-X-100 in PBS) was applied for 1 hour at room temperature then samples were rinsed extensively in PBS and incubated in primary antibody (as above) diluted in antibody blocking solution overnight at $4 \mathrm{iC}$. The next day, samples were washed in three changes of PBS for a total of 1 hour and then incubated with fluorescently tagged secondary antibodies (as above) for 4 hours at room temperature. Samples were washed for 1 hour before observation under a Leica MZFLIII dissecting fluorescent microscope or mounting under a coverslip using Vectashield mounting medium with DAPI (Vector Laboratories). Fluorescent microscopy was carried out on a Zeiss Axioskop fluorescent microscope as above.

\section{Confocal microscopy and cell counting}

Lung and midgut tissues obtained from E6 GFP-grafted chick embryos were examined using confocal microscopy (Zeiss LSM 710 confocal microscope). Z-stack images of lung and gut double immunostained for GFP and TuJ1 were acquired for GFP/Alexa568 and DAPI. Equivalent volumes of $134 \times 134 \times 50 \mu \mathrm{m}$ were imaged from 6 different field of view regions of the 
lung and the midgut ( $\mathrm{n}=3$ different embryos examined). After reconstructing the z-stack images using a 3D viewer, GFP+ cells were counted using the Image-J Fiji cell counter plugin and plotted to a histogram.

\section{Acknowledgements}

Fertilised GFP chicken eggs were supplied by Prof. Helen Sang, The Roslin Institute, University of Edinburgh, from projects supported by the Biotechnology and Biological Sciences Research Council (BBSRC) and the Wellcome Trust. DCC wildtype and mutant littermate mouse embryos were obtained from Dr. Elyanne Ratcliffe, Division of Gastroenterology and Nutrition, McMaster University, Canada. LJF was funded by a PhD studentship from the Anatomical Society, UK.

\section{References}

BARLOW, A.J., WALLACE, A.S., THAPAR, N. and BURNS, A.J. (2008). Critical numbers of neural crest cells are required in the pathways from the neural tube to the foregut to ensure complete enteric nervous system formation. Development 135: 1681-1691.

BARRAUD, P., SEFERIADIS, A.A., TYSON, L.D., ZWART, M.F., SZABO-ROGERS, H.L., RUHRBERG, C., LIU, K.J. and BAKER, C.V. (2010). Neural crest origin of olfactory ensheathing glia. Proc Natl Acad Sci USA 107: 21040-21045.

BURNS, A.J. (2005). Migration of neural crest-derived enteric nervous system precursor cells to and within the gastrointestinal tract. Int J Dev Biol 49: 143-150.

BURNS, A.J., CHAMPEVAL, D. and LE DOUARIN, N.M. (2000). Sacral neural crest cells colonise aganglionic hindgut in vivo but fail to compensate for lack of enteric ganglia. Dev Biol 219: 30-43.

BURNS, A.J. and DELALANDE, J.M. (2005). Neural crest cell origin for intrinsic ganglia of the developing chicken lung. Dev Biol 277: 63-79.

BURNS, A.J. and LE DOUARIN, N.M. (1998). The sacral neural crest contributes neurons and glia to the post- umbilical gut: spatiotemporal analysis of the development of the enteric nervous system. Development 125: 4335-4347.

BURNS, A.J. and LE DOUARIN, N.M. (2001). Enteric nervous system development: analysis of the selective developmental potentialities of vagal and sacral neural crest cells using quail-chick chimeras. Anat Rec 262: 16-28.

BURNS, A.J., THAPAR, N. and BARLOW, A.J. (2008). Development of the neural crest-derived intrinsic innervation of the human lung. Am J Respir Cell Mol Biol 38: 269-275.

DELALANDE, J.M., BARLOW, A.J., THOMAS, A.J., WALLACE, A.S., THAPAR, N., ERICKSON, C.A. and BURNS, A.J. (2008). The receptor tyrosine kinase RET regulates hindgut colonization by sacral neural crest cells. Dev Bio/313:279-292.

FREEM, L.J., ESCOT, S., TANNAHILL, D., DRUCKENBROD, N.R., THAPAR, N. and BURNS, A.J. (2010). The intrinsic innervation of the lung is derived from neural crest cells as shown by optical projection tomography in Wnt1-Cre;YFP reporter mice. J Anat 217: 651-664.

GERSHON, M.D. (2010). Developmental determinants of the independence and complexity of the enteric nervous system. Trends Neurosci 33: 446-456.

HAMBURGER, V. and HAMILTON, H.L. (1951). A series of normal stages in the development of chick embryo. J Morphol 88: 49-92.

HARRIS, M.L. and ERICKSON, C.A. (2007). Lineage specification in neural crest cell pathfinding. Dev Dyn 236: 1-19.

HEANUE, T.A. and PACHNIS, V. (2007). Enteric nervous system development and Hirschsprung's disease: advances in genetic and stem cell studies. Nat Rev Neurosci 8: 466-479.
JIANG, Y., LIU, M.T. and GERSHON, M.D. (2003). Netrins and DCC in the guidance of migrating neural crest-derived cells in the developing bowel and pancreas. Dev Biol 258: 364-384

KALCHEIM, C. and LE DOUARIN, N.M. (1999). The Neural Crest. Cambridge University Press, Cambridge.

KUO, B.R. and ERICKSON, C.A. (2010). Regional differences in neural crest morphogenesis. Cell Adh Migr 4: 567-585

KUO, B.R. and ERICKSON, C.A. (2011). Vagal neural crest cell migratory behavior: a transition between the cranial and trunk crest. Dev Dyn 240: 2084-2100.

LARANJEIRA, C. and PACHNIS, V. (2009). Enteric nervous system development: Recent progress and future challenges. Auton Neurosci 151: 61-69.

LE DOUARIN, N.M. (1969). Particularities du noyau interphasique chez la Caille japonaise (Coturnix coturnix japonica). Utilisation de ces particularites comme "marquage biologique" dans des recherches sur les interactions tissulaires et les migrations cellulaires au cours de l'ontogenese. Bull. biol. France Belg. 103 435-452.

LE DOUARIN, N.M. and TEILLET, M.A. (1973). The migration of neural crest cells to the wall of the digestive tract in avian embryo. J Embryol Exp Morphol 30: 31-48.

MCGREW, M.J., SHERMAN, A., ELLARD, F.M., LILLICO, S.G., GILHOOLEY, H.J. KINGSMAN, A.J., MITROPHANOUS, K.A. and SANG, H. (2004). Efficient production of germline transgenic chickens using lentiviral vectors. EMBO Rep5:728-733.

MCGREW, M.J., SHERMAN, A., LILLICO, S.G., ELLARD, F.M., RADCLIFFE, P.A., GILHOOLEY, H.J., MITROPHANOUS, K.A., CAMBRAY, N., WILSON, V. and SANG, H. (2008). Localised axial progenitor cell populations in the avian tail bud are not committed to a posterior Hox identity. Development 135: 2289-2299.

PETERS-VAN DER SANDEN, M.J., KIRBY, M.L., GITTENBERGER-DE GROOT, A., TIBBOEL, D., MULDER, M.P. and MEIJERS, C. (1993). Ablation of various regions within the avian vagal neural crest has differential effects on ganglion formation in the fore-, mid- and hindgut. Dev Dyn 196: 183-194.

ROTHMAN, T.P., LE DOUARIN, N.M., FONTAINE-PERUS, J.C. and GERSHON M.D. (1990). Developmental potential of neural crest-derived cells migrating from segments of developing quail bowel back-grafted into younger chick host embryos. Development 109: 411-423.

ROTHMAN, T.P., LE DOUARIN, N.M., FONTAINE-PERUS, J.C. and GERSHON M.D. (1993). Colonization of the bowel by neural crest-derived cells re-migrating from foregut backtransplanted to vagal or sacral regions of host embryos. Dev Dyn 196: 217-233

RUHRBERG, C. and SCHWARZ, Q. (2010). In the beginning: Generating neural crest cell diversity. Cell Adh Migr 4: 622-630.

TEILLET, M.A., ZILLER, C. and LE DOUARIN, N.M. (2008). Quail-chick chimeras. Methods Mol Biol 461: 337-350.

TOLLET, J., EVERETT, A.W. and SPARROW, M.P. (2001). Spatial and temporal distribution of nerves, ganglia, and smooth muscle during the early pseudoglandular stage of fetal mouse lung development. Dev Dyn 221: 48-60.

WALLACE, A.S. and BURNS, A.J. (2005). Development of the enteric nervous system, smooth muscle and interstitial cells of Cajal in the human gastrointestinal tract. Cell Tissue Res 319: 367-382.

YNTEMA, C.L. and HAMMOND, W.S. (1954). The origin of intrinsic ganglia of trunk viscera from vagal neural crest in the chick embryo. J Comp Neurol 101: 515-541.

YOUNG, H.M., HEARN, C.J., CIAMPOLI, D., SOUTHWELL, B.R., BRUNET, J.F. and NEWGREEN, D.F. (1998). A single rostrocaudal colonization of the rodent intestine by enteric neuron precursors is revealed by the expression of Phox $2 \mathrm{~b}$, Ret, and p75 and by explants grown under the kidney capsule or in organ culture. Dev Biol 202: 67-84. 


\section{Further Related Reading, published previously in the Int. J. Dev. Biol.}

Matrix metalloproteinase-2 is involved in the migration and network formation of enteric neural crest-derived cells Richard B. Anderson

Int. J. Dev. Biol. (2010) 54: 63-69

Mouse G-protein gamma3 expression in the developing CNS and neural crest cell derivatives

Gregory M. Kelly, Yukio Saijoh, Ariel Finkielsztein and Steve Mangos

Int. J. Dev. Biol. (2008) 52: 1143-1150

\section{Mouse-chick neural chimeras}

Josiane Fontaine-Pérus and Yvonnick Chéraud

Int. J. Dev. Biol. (2005) 49: 349-353

Migration of neural crest-derived enteric nervous system precursor cells to and within the gastrointestinal tract

Alan J. Burns

Int. J. Dev. Biol. (2005) 49: 143-150

Involvement of endothelin receptors in normal and pathological development of neural crest cells

Patrick Pla and Lionel Larue

Int. J. Dev. Biol. (2003) 47: 315-325

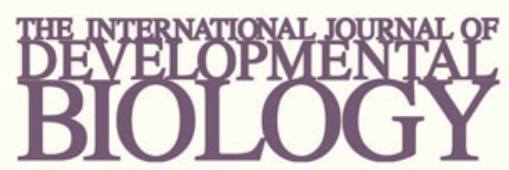

Volume 54 Nos. $6 / 7$

Special Issue

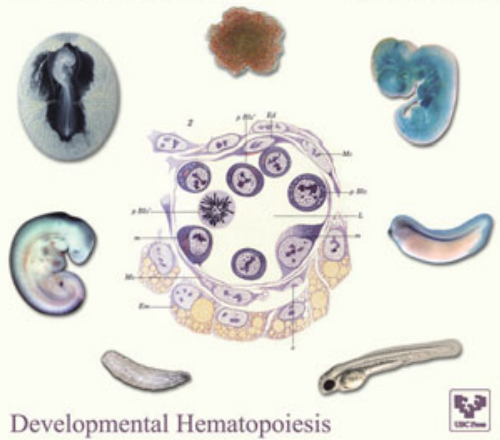

5 yr ISI Impact Factor $(2010)=2.961$
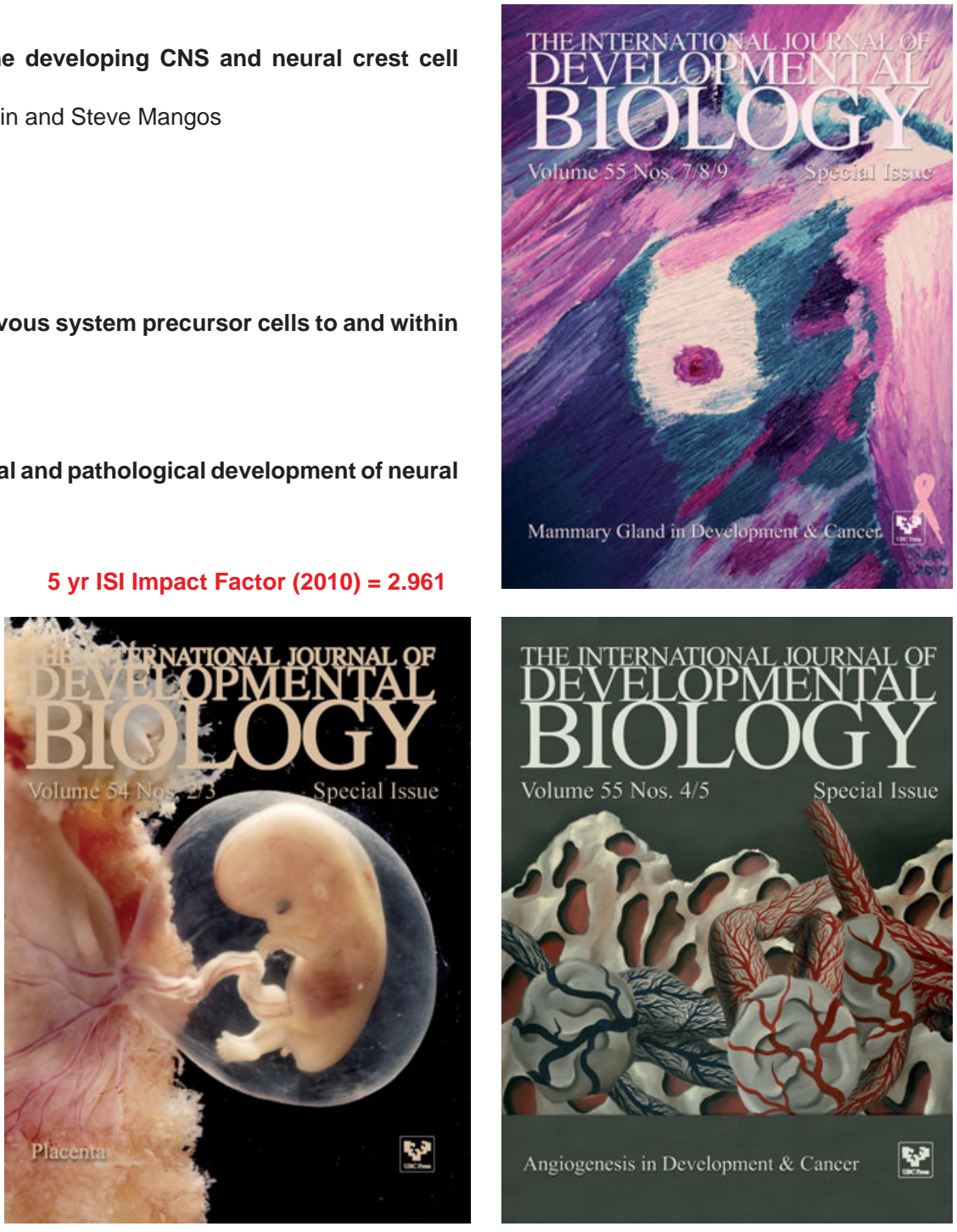

THE INTERNATIONAL
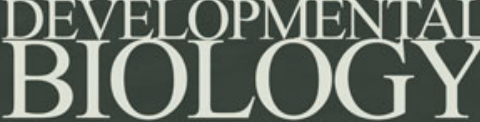

Volume 55 Nos. 4.5

Special Issue

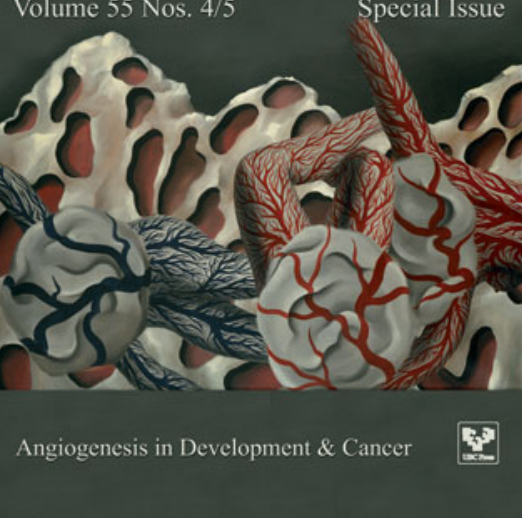

